\title{
ISSUE OF YOGA ON PHYSICAL AND MENTAL HEALTH
}

\author{
Silvia Horváthová 1 , Iveta Petríková Rosinová ${ }^{2}$
}

\begin{abstract}
The effect of yoga on human health has long term interest. In this regard, we view the effect on physical health, not only mental, in terms of the sensory input. This paper attempts to present a position on whether yoga affects human health status and limits an increase in lifestyle diseases. In this work, we collect data and use inductive reasoning methods with the aim of generalizing conclusions. Our findings indicate the effect of yoga, not only on mental health, but also in terms of physical health, in particular in reducing obesity. It is concluded that to find a completely healthy person is rare, but with various relaxation techniques of yoga, one can eliminate a variety of ailments and benefit overall in health.
\end{abstract}

UDC Classification: 613.7 DOI: http://dx.doi.org/10.12955/cbup.v4.833

Key words: health, harmony, body, benefits, obesity.

\section{Introduction}

Although people feel healthy, they may suffer from underlying disorders that cause destructive effects on their body and at some time form a more serious functional defect. It is then that the person visits a doctor, who may or may not provide a way to intervene in the patient's health. Overall the person may feel relieved, and possibly feel health again because of a change in consciousness. However, the person will likely return to previous pathways in their journey through life, and continue to irritate the already impaired functioning of the body, which may again, after some time, display ailments.

\section{Issue of health}

Continuing in this way long-term, may result in organ diseases. Regardless of which organ, the causes of organ disease lie in a lack of functional order due to a flawed way of living. This lack of order can be transmitted to progeny, initially as susceptibility to dysfunction in the organism and later directly as a congenital organ abnormality. The true cause of defects in the body may be of spiritual character. However, the term 'spiritual' needs to be understood as natural, with character so subtle that it is beyond the limits of possible discernment by a person with average observational abilities. We refer to the orientation of consciousness. What does this mean in relation to the question of health? The consciousness is, from the perspective of forces, only a phenomenon, i.e. a reflection board for perceptions and thus, a representation that is indefinable from the material point of view. Nevertheless, it is considered, in principle, a force, that directs a life-giving substance and therefore, a force bringing life to the body (Vícha, 2011). A person who is within their consciousness, constantly unaware of their body, emits a life-giving substance outside of their body. This substance is called 'quintessence', which for human health may be the ultimate and most decisive factor in the field of inner functions.

Therefore, the consciousness, as the essence of vitality, should continuously, by means of concentrated attention, focus on the body, in order to prevent diseases altogether. However, this requires a total change in the way of life for a person, and will be adopted only by someone who cares about harmonizing their health. A human is 'weak' and therefore would rather refer to doctors for mending a 'wound', a wound from which the life-giving force gushes; a wound that is self-inflicted through a life oriented only and solely on the external world.

While referring to awareness as an important factor in the question of health, we do not intend to claim that awareness of the physical existence is purely a spiritual phenomenon. We consider it an effect of the chemical processes of digestion, which at its highest consequence in the living world enables a person to be in contact with the etheric principle of the cosmic space. This principle has a spiritual nature and through assimilation with the consciousness of the being, characterizes the human being as an individual, capable of objective awareness, which we call 'an awareness on its own' or an

\footnotetext{
${ }^{1}$ Silvia Horváthová, University of Sts. Cyril and Methodius, Institute of Physiotherapy, Balneology and Rehabilitation, Rázusova 14, 92101 Bratislava, Slovakia, silvia.horvathova@ucm.sk

${ }^{2}$ Iveta Petríková Rosin, Alexander Dubcek University of Trencin, Faculty of Health, Student 291101 Trenčín, Slovakia, iveta.rosinva@tnuni.sk
} 
'impersonal consciousness'. If we understand and find this contact point of the two qualities, which are similar to each other, i.e. the consciousness of a being and the etheric principle of the cosmic space, nourishment can take place at this point. Thus, we have worked through to a place where a human is nourished not only by the course of food, but also by the essences of space. These essences enliven a human in a sense that their consciousness is vigilant; those who lack these contacts have a sluggish consciousness (Yuesudian, 1989).

Therefore, we have arrived at the level where a person appears as a creature living in cosmic essences. If the hyperactive and unceasing thinking is not at this level, then the assimilation process that originates in the contact of the 'consciousness on its own' with the cosmic essences, would contribute to the transfer of these essences into the body. The body would then be nourished, other than by food that it chemically transforms into high spiritual modifications of forces, by the essential force of the universe, which would greatly contribute to preserving the body's health status in a perfect order. However, a human think. They think so much that they waste the absorbed cosmic force of essences and thus depend solely on food. Food seems to be low in etheric elements and therefore, a human is continuously undernourished to an unnoticeable extent. Due to this reason, humans suffer from aging, i.e. from the deficit of fluids necessary for proper performance. In addition, the essential forces are separated from the human being that functions, as a consequence of excessive thinking, by means of chemically transformed food only, and the problem of health is thus unsolvable by currently existing means (Budig, 2012). No matter how one forces the organs to function properly by the unnoticeable effects of the drastic medications, they will not manage, apart from an immediate chemical stimulation, to force the organs to assimilate the essential forces satisfactorily. Due to this reason, it is desirable that a person considers the problem of health from a different perspective than that of mechanical processes in the physical body. It is necessary to go beyond the materialistic view of life as a series of functions and chemical processes, because by doing so likely finds an existence of a factor that determines health. This factor is proper nourishment at the contact point of the consciousness of being and the cosmic essences.

Exactly at the contact point of the consciousness of being and the essential cosmic forces, a process of nourishment by the energetic essences takes place. The vibrational character of these energetic essences is analogous to the thermal life force that gives vitality to the body. This originates in the chemical processes of the material food, and transforms itself into material waste products, entering the lymph system and finally leaving the body as etheric substances of a gaseous nature. As long as a person can assimilate, through the essential functional processes, the essential forces of the cosmos, and possibly of nature, their health remains in balance due to functions of this kind being in order. However, if a person casts these essential forces into space by excessive thinking, he or she disturbs the vital functioning of the essential factors and, subsequently, their bodies will deteriorate due to lack of life-giving forces. This concept suggests to us that it is necessary for all to pay attention to the 'right way of living' in their thoughts. Communication is an important aspect of medical activity (Rosinová, 2013).

If such 'thinking' is correct from the point of view of a way of living, any loss of emitting etheric substances is prevented. These substances will, irrespective of the will of the person, carry out their work for beneficial health. Due to this reason, people who are unconcerned in matters of the external world are healthier, at least on average. On the contrary, highly mentally active people are literally digesting their body; if generations act in this way, a fragile physical system, susceptible to numerous disorders will manifest. It is known that 'nervous' people, who cannot control inner activity with focus upon external things, generally have 'fragile' health. The reason is an excessive emission of the essential life forces, which results in loss of life-giving substances from the body that then suffers from deficiencies. If it sometimes seems that a person is nervous due to the disharmonic functions in the body, it is only because they are unaware of the real root of this state. However, it is certain that a person suffering from nervous ness can only start an appropriate way towards inner living with great difficulty, while in this state. Overall, it is a matter of will and perseverance. Notably, the state of inner exhaustion is very advanced in all people, and what should be suggested here is precaution and not an allopathic intervention in a crisis (Minárik, 2012).

Beneficial health is thus only a by-product of the yogic effort. Whether the person striving for yoga desires it or not, they employ psychological material, which we have termed, 'the essential force'. 
Thus, the stand a person holds on the desirable self-discipline matters as it requires them to maintain inner harmony. Specifically, with regard to this inner harmony (or disharmony), one can improve or worsen their health by yogic efforts. From our experience regarding this matter, a person needs to be particular about this harmony and in that regard strengthen their body by yogic efforts, because the intrusive influences become stronger with striving in yoga practice in precise proportion to inner disharmony. Thus, if a person pays no attention to such influences, they will eventually find they are walking an undesirable path. In any case, these intrusive influences have an unfavorable effect in the later stages of inner development, which in yoga is considered above all else. A disturbed functional harmony more or less, according to the extent of disorders, deters a person from realizing such a qualitatively high concentration that would provide them with the necessary understanding of the highest state of being aware of oneself without support or limitation, which is the goal of the yogis (Mináirik, 2012).

\section{Physical benefits of yoga}

A regular practice of yoga improves all body systems: skeletal, muscle, skin, circulatory, nervous, digestive, respiratory, endocrine, excretory, and the reproductive.

It improves strength and tones all muscles

The benefits of a yoga asana include strengthening every muscle of the body. A well-balanced practice includes positions that serve to increase both strength and relaxation. There is an asana for arms and especially the upper body. Another involves standing, which maintains a large work out for the legs and another that works the abdominals.

Increase flexibility

Certain flexibility improvements are popular post-employment benefits of yoga. Keeping joints, tendons, and muscles flexible, flexibility is imperative for a person to avoid injury and remain fit. For example, many people who suffer from arthritis have incredible relief through yoga. In addition, greater flexibility improves the alignment of the body and posture and therefore relieves pain in the back and neck, which are problems for many people. The muscles, ligaments, and tendons stretch and acquire noticeable elasticity.

Increase the life energy

Most people would want to be more active and energetic during the day. If energy could be packaged and sold, it would be the best selling item in the world. Yoga reduces stress, allows muscles to relax and contract, and balances the whole body. These benefits not only help people sleep better, but reduced effort is required overall and, in general, there is an increase in energy throughout the day. Yogis believe that active practice balances the energy centers (chakras in Sanskrit), allowing the life force (prana) to flow freely throughout the body, and this dramatically increases vitality. Pranayama uses the breathing techniques to increase such vital energy.

Rebalance the entire body

Balance benefits from yoga positions practiced during yoga classes using different muscles and movements promote balance throughout the body. The physical balance increases stability and coordination, which in turn greatly reduces the risk of injuries. Also, to "be balanced" refers to the state of balance that the body can regain and maintain with regular practice. When all systems, both internal and external, are in balance, humans experience a state of indescribable health.

Improved digestion and weight loss

Improved digestion is a benefit of yoga from a combination of physical exercise, and mental techniques for stress reduction that also help balance the entire digestive system. With this system in equilibrium, day after day, and with healthier eating habits, a person can achieve optimal weight for their physique. This is because many positions provide twists, inversions, and the use of abdominal muscles, which act to rebalance the abdominal organs. Also, asanas are exercises that will lead a person towards achieving their ideal weight for their body with time and constant practice. If a person's aim is to regain an ideal weight and eat 'well', then yoga is the 'perfect' approach. A recent and relevant article on food is: How to stop eating too much and hurt immediately. 
Human beings are naturally equipped with the abilities of inner life, i.e. the ability to be aware of the external world, ability to remember and ability to think within these dimensions of thinking logically from which to draw conclusions. The first two inner abilities are bound by inborn predispositions; and the third can be developed by an interested person. Most people live in such a way that they are primarily interested in obtaining as many sensory perceptions and impressions as possible and with these 'rippling' feelings they demand their experiences of pleasurable feelings. As a consequence, they have no regard for conscious thinking, which is very important for mental health; only conscious thinking is logical. Such people, draw conclusions from their innate mental capacity of thinking, with thinking that becomes reflexive because it is uncontrolled. Such thinking only becomes active by means of stimuli from sensory perceptions; and by this, it is subject to gradual degeneration and pathological states (Makris, 2015).

As a prognosis, those who have no interest in developing conscious thinking are exposed to mental degeneration. A result of this is the senile mental deficiency and mental delusions of old age.

It is difficult to determine an absolutely certain prognosis of the mental development of people who think reflexively. Conscious thinking cannot be easily distinguished from reflexive thinking, nor isolated from it. Even a mentally alert and able youth can suffer from reflexive thinking and therefore from mental inactivity, if it is understood as passivity or laziness. It could be said that the only preventive measure against this state is continuous effort to learn of everything. The sphere of interests of each individual has indeed a crucial role in this. Based on innate inner predispositions, these interests mostly lie in sensory pleasures, in technology or natural sciences, as they are commonly understood. In such a case, a person mentally 'leaves themselves', and even when thinking becomes logical, there is no guarantee that they will avoid mental disorders that occur with age. Thus, a person becomes a 'mental type', whose pathological prospects differ to those exposed to the mentally inactive and idle types without interests; however, with the exception of those who are desirous of sensory experiences.

\section{Conclusion}

Yoga represents an attaining of unity in personal and universal consciousness, and thus is a method based on states and processes in the psyche that predominantly influence the body, and from there on, the state of consciousness. The yogi, who adheres to the basic rules of yoga, namely: inner balance, tranquil mind, and 'thinking in goodness', will generally feel its beneficial influence on health, initially in the functional sense and, in a more advanced stage, in the body's organs. The only exception relates to that of a resolute will to realize cosmic consciousness. In that case, a person becomes a mystic, who wants to terminate their sorrowful inner states, often at the expense of the harmonizing influence on health, because they sense or recognize that the highest realization terminates every suffering, including suffering from ill health. It is concluded that to find a completely healthy person is rare, and various relaxation techniques of yoga help eliminate a variety of ailments and improves health

\section{References}

Budig, K. (2012). The Women's Health Big Book of Yoga: The Essential Guide to Complete Mind/Body Fitness. London: Rodale Books. 45-47.

Makris, K. (2015). NEW Autoimmune Illness and Lyme Disease Recovery Guide. London: Skyhorse Publishing Compnay. 17-19.

Minárik, K. (2012). Yoga and Buddhism in the life of a contemporary person. Praha: Canopus. 78-82.

Rosinová, I. P. (2013). Komunikácia ako dôležitý aspekt v zdravotníctve. In. D. Kubíčková, Stratégie sociálnej politiky v kontexte zvyšovania sociálneho statusu seniorov. Trnava: Trnavská univerzita [Communication as an important aspect of health. In. D. Kubíčková, strategies of social policy in the context of improving the social status of the elderly. Trnava University of Trnava]. 95-105.

Vícha, F. (2011). Jóga a zdraví (Praktická jogoterapie) [Yoga and Health (Practical jogoterapie)]. Bratislava: Eko - konzult. 34-35.

Yuesudian, S. (1989). Health and Yoga. Cannbera: Allen and Ulwin. 23-27. 